\title{
Contaminated groundwater sampling and quality control of water analyses
}

Trick J K, Stuart M and Reeder S

\begin{abstract}
The objective of groundwater sampling for site characterisation is the collection of samples that represent the underlying conditions at a site and ensuring that sample integrity is maintained from field to laboratory. The authors describe the tools available to the field sampler for the collection of groundwater samples, methods of on-site water quality analysis and the appropriate preservation and handling of samples. There are a variety of portable sampling devices available for the collection of groundwater, however, each application has different requirements and is dependant on the contaminant(s) of interest and most importantly, the specification of the borehole to be sampled. A number of different sampling devices and their applicability are presented. Traditionally, to ensure sample representivity the removal of stagnant water from a monitoring well was accomplished by purging a fixed number of well volumes, generally between three to five volumes, prior to sample collection. In recent years research has shown that low-flow purging (pumping at a rate that doesn't disturb the stagnant water in a well) produces samples that are representative of the formation water. In addition 'no purge' sampling is becoming an increasingly accepted method of collecting representative groundwater samples for some determinands, in particular VOCs and some metals using diffusion methods. The merits of different purge methodologies are discussed. On-site water quality measurements are carried out predominantly to monitor effective purging of water at the sampling point before sample collection, and to measure unstable parameters that cannot be subsequently reliably determined in the laboratory. On-site measurements such as $\mathrm{pH}$, Specific Electrical Conductance (SEC), Oxidation Reduction Potential (ORP), Dissolved Oxygen (DO), Temperature and alkalinity can be used to provide a check on a subsequent laboratory analysis. Techniques for the preservation and analysis of samples and quality assurance and quality control are also presented.
\end{abstract}

\section{INTRODUCTION}

Contaminated sites may pose risks to both the environment and human health. The impacts of contaminated sites in the UK and internationally are managed using a conceptual risk based assessment model:

\section{Source $\Rightarrow$ Pathway $\Rightarrow$ Receptor}

The source is defined by the amount and nature of a potentially hazardous contaminant. The degree to which a source poses a risk depends on the presence of a means of transport (the pathway) for the contaminants to the receptor (the plants, animals and/or humans and even buildings that may be adversely affected by the contamination). Contaminants can move from the source to the receptor via food, soil, air and water. For humans, the main ways that contaminants can enter our bodies are by ingestion, inhalation and direct contact, for example, by absorption through the skin.

It is important to note that groundwater and surface water may act both as pathways (e.g. through percolation through the unsaturated zone, saturated groundwater flow and surface water flow) and receptors (e.g. vulnerable water abstractions, resources or ecological systems). Evaluation of surface and groundwaters as part of contaminated site investigation studies is, therefore, a major concern.

This paper aims to provide a step by step guide for practitioners involved in the collection of contaminated samples by reviewing current groundwater sampling techniques and procedures and highlighting the major sources of uncertainty associated with sample collection. On-site water quality measurements, quality assurance procedures and sample handling techniques designed to maintain the representativeness of the sample from field to laboratory are also discussed..

\section{GROUNDWATER SAMPLING OBJECTIVES}

The critical objective of groundwater sampling for site characterisation is to collect representative samples and to ensure that their integrity is maintained from field to laboratory. Sampling and analysis can be expensive so it is important that a thorough understanding of the site conditions is determined prior to mobilising a field sampling team. For example, groundwater quality can be variable over quite short distances; therefore, an understanding of the hydrogeology and flow dynamics of a system is important before any water quality sampling is undertaken. Preparing a robust conceptual model of the site in advance will help to guide the type of sample, analysis and sampling protocol required. 


\section{Planning and Preparation}

A successful groundwater sampling campaign needs to be planned meticulously prior to mobilisation of the sampling team. It is important to ensure that all paperwork and relevant information is available to the team. This will include: maps of the site detailing borehole locations; borehole details, including purge volumes and completion details; analytical requirements, including bottle types, preservation techniques and on-site measurement requirements; sample sheets and bottle labels; contact details for site supervisors, laboratories, couriers, etc; data from previous sampling rounds for comparison; and health and safety documentation read and signed by all field operatives.

\section{CHOOSING THE RIGHT PORTABLE SAMPLING DEVICES}

There are a variety of portable sampling devices available for the collection of representative groundwater samples, however, each application has different requirements and is dependant on the contaminant(s) of interest and, most importantly, the specification of the borehole to be sampled. The first factors to consider are the depth to the water table and the borehole diameter; other factors including the borehole completion (e.g. open hole, length of screened interval, casing diameter, purge volume required) also need to be considered. In addition, the sampling device should satisfy the following requirements (Schuller et al., 1981):

- the device must not alter the physical or chemical structure of the sample;

- the materials used in the construction of the device must not leach or absorb contaminants to or from the sample;

- the device must be portable and easy to mend in the field;

- the device must be easily cleaned to avoid cross-contamination;

- chemical parameters such as $\mathrm{pH}, \mathrm{ORP}$ (oxidation-reduction potential) dissolved oxygen and temperature must not be altered by the pumping mechanism;

- the device should be inexpensive, durable and simple to use.

Comparisons of the different sampling mechanisms available are given by Barcelona et al. (1984), Stuart (1984), Nielsen and Yeates (1985) and Pohlmann and Hess (1988). A comprehensive literature review of the effects of sampling devices on water quality is given by Parker (1994).

Portable sampling devices were categorised by Nielsen and Yeates (1985) as: grab samplers, suction lift devices and positive displacement mechanisms. A brief review of each category is given below.

\section{Grab Samplers}

The most common grab sampler is the bailer, of which there are several types available. Essentially, the bailer is a rigid tube made of PVC, stainless steel or Teflon, with a ball valve at the bottom and an open top. As the bailer is lowered to the required depth, groundwater flows up through the ball valve and out through the open top. Once the bailer is no longer in motion, the pressure of the water column closes the ball valve and seals in the sample. Double valve bailers have valves top and bottom that are both closed upon reaching the required depth; this stops inflow and mixing of water during the bailer's ascent to the surface. Bailers are generally inexpensive (stainless steel bailers are the exception) and fulfil most of Nielsen and Yeats' criteria for the 'ideal' sampling tool. They can be dedicated to individual monitoring wells to avoid cross contamination between boreholes, they are portable, simple to use and relatively easy to clean. They are, however, not suitable for purging large volumes of water, and it can be difficult even with double ended bailers to determine accurately where the sample was collected. Compared to other sampling devices, the operator is also more at risk of coming into contact with contaminated sample, especially when emptying the bailer.

\section{Passive diffusion bag sampler (PDB)}

Passive Diffusion Bag (PDB) sampling takes advantage of the Fick's Law of Diffusion, which states that compounds will migrate from an area of high concentration to an area of low concentration until equilibrium is achieved. A typical PDB sampler consists of a low-density polyethylene, 'lay-flat' tube closed at both ends and filled with deionised water prior to deployment. The sampler is positioned at the target horizon of the well by attachment to a weighted line or fixed pipe. The sampler is used to obtain concentrations of volatile organic compounds (VOCs) in groundwater from wells or at interfaces of groundwater and surface water. The molecular size and shape and hydrophobic nature of a compound 
influences its ability to diffuse through the polyethylene membrane and thus PDB samplers are not appropriate for all VOCs. PDBs are not suitable for assessment of inorganic species.

\section{SnapSampler ${ }^{\mathrm{TM}}$}

The SnapSampler ${ }^{\mathrm{TM}}$ relies on passive flow-through of water through well screens. It is simple to use and there is minimal field pre-preparation. The sample bottles are open at both ends to the well environment during the deployment period and contaminants do not have to diffuse through a membrane. Less equilibration time is needed before sampler retrieval and contaminants such as MTBE, 1,2,4-

trimethylbenzene, and acetone are not selectively inhibited from entering the sampler. The no-pour aspect of the device is unique among common sampling protocols, whether traditional purge or passive. Historic and recent research on VOC sampling techniques indicates that minimising sample transfer steps also minimises VOC losses. This method eliminates all transfer steps outside the laboratory analytical equipment. There are currently no published studies that have evaluated this device.

Figure 1 Stainless steel bailer being deployed down a $50 \mathrm{~mm}$ monitoring well

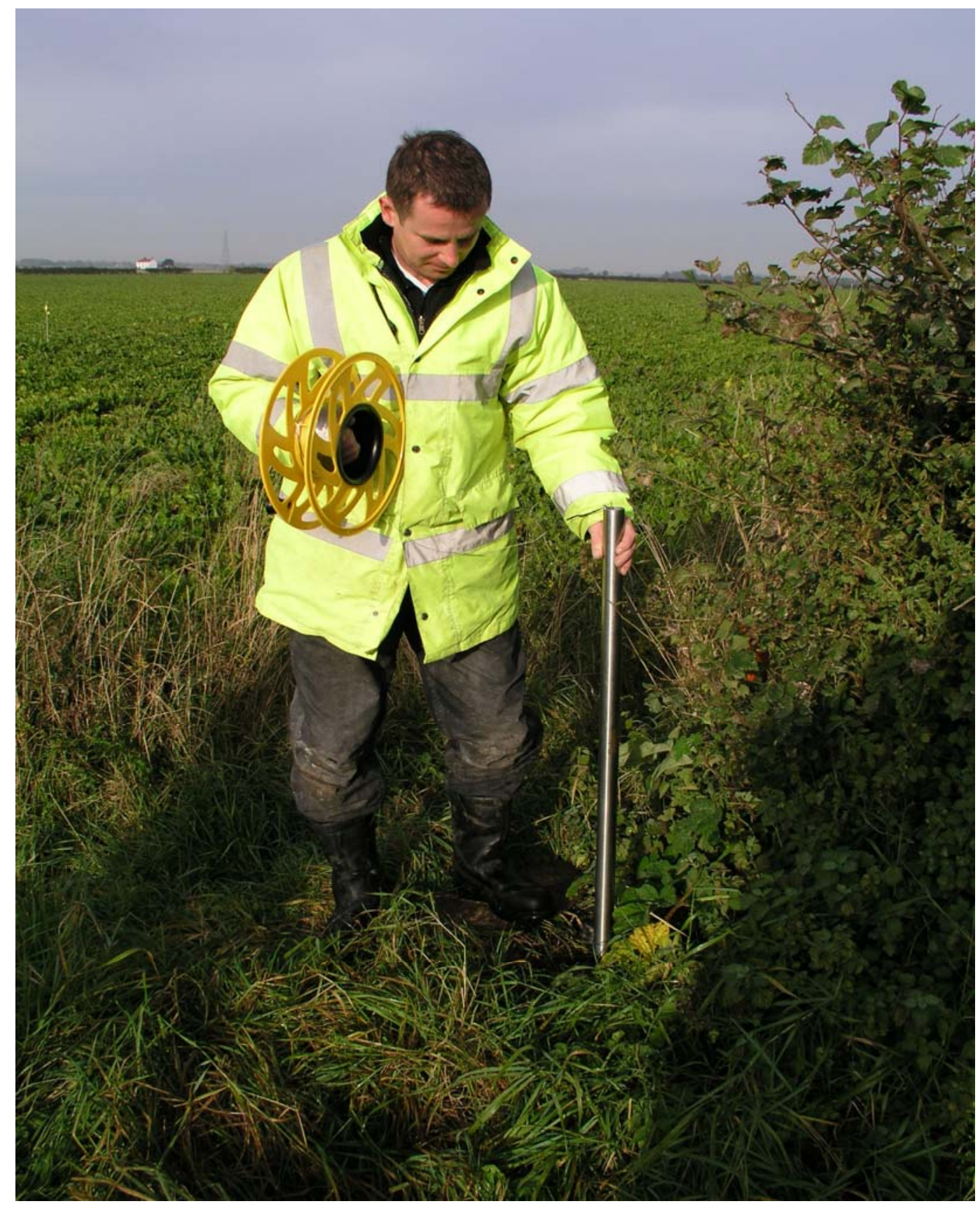




\begin{abstract}
HydraSleeve $^{\mathrm{TM}}$
The reported advantages of the HydraSleeve ${ }^{\mathrm{TM}}$ are similar to the PDB. Sladky and Roberts (2002) tested the HydraSleve ${ }^{\mathrm{TM}}$ for its applicability to sample semi-volatile organic compounds (SVOC) by comparison with low-flow purging and bottom-loading bailer samplers. Results showed that wells containing LNAPLs were not suited to be sampled using this method and that SVOC concentrations were on average $17 \%$ higher than low-flow samples and 150\% higher than samples collected using a bottom loading bailer. Parker and Clark (2002) compared the HydraSleve ${ }^{\mathrm{TM}}$ to four other discrete interval samplers and found it yielded representative samples of pesticides, explosives and metals, although the authors recommend that it be used only in low turbidity wells.
\end{abstract}

\title{
Inertial Pumps
}

The inertial pump is described for use in groundwater monitoring wells by Rannie and Nadon (1988). The pump consists of just two components: a foot valve, which can be manufactured in High Density Polyethylene (HDPE), Delrin (an acetal resin thermoplastic that has high strength, rigidity, durability and chemical resistance), Teflon or stainless steel; and a riser tube, also made from HDPE or Teflon. The operating principle of the pump is based on the inertia of a column of water within the riser tubing. Once installed, the water level in the tubing is equal to that of the well. A rapid upstroke closes the foot valve and lifts the water column in the tubing a distance equal to the stroke length. The water column continues to move up the riser tubing due to its inertia. A down stroke opens the foot valve, forcing water to flow into the tubing thus raising the water level. Rapid up and down movement of the tubing causes the water to rise up the tubing to the surface. Flow rates of between 1.8 and 6.5 litres per minute were reported depending on the foot valve size, and depths of $40 \mathrm{~m}$ (manual operation) and $60 \mathrm{~m}$ (motor driven) were achieved. As with bailers, this device fulfils most of the requirements of the 'ideal' sampling device as described above, however, manual operation is labour intensive and the use of a motorised device requires a compressor or generator, thus reducing the portability of the system.

\section{Peristaltic pumps}

Suction lift pumps operate by applying a vacuum to a sample line or tube causing water to be drawn up to the surface. This limits these devices to sampling groundwaters at depths no greater than $7.6 \mathrm{~m}$ (Nielsen and Yeates, 1985). Peristaltic pumps operate by creating a low vacuum by the squeezing action of rollers on flexible tubing, as the rollers rotate around the tubing, suction is created drawing sample up from the well. These pumps have an advantage over centrifugal pumps (see below) in that the sample only comes into contact with the tubing. However, silicone tubing is most commonly used, to provide the required flexibility, and this is not suitable for sampling organics due to its propensity to absorb organic compounds (Barcelona et al., 1985; Pearsall and Eckhardt (1987). The loss of volatiles using peristaltic pumps has been investigated by a number of workers; Barker and Dickhout (1988) found concentrations of volatile halocarbons 23 to 33 percent lower than other pumps tested and concluded that degassing was a problem with this pump. Both pumps require a power source such as a generator or $12 \mathrm{~V}$ batteries.

\section{Gas-Operated Bladder Pumps}

There are several designs of bladder pumps, however, the basic design is one of a long rigid casing (often stainless steel) housing a flexible membrane. The bladder, which has a perforated tube inside, is attached to a screened intake check valve and a discharge valve attached to a discharge tube to take sample to the surface. The annulus between the bladder and the housing is pressurised prior to insertion in the well causing the bladder to collapse. When a sample is to be taken, the annulus pressure is reduced, as the water pressure at the intake valve exceeds that of the annulus, and water flows into the bladder through the perforated tube. When the bladder is full, pressure is increased in the annulus causing the bladder to collapse, closing the intake valve and forcing the water up through the discharge valve and into the discharge tube. The annular gas is then vented to the surface allowing the bladder to be re-filled and the cycle repeated. Regulating the frequency of the applied and released pressure allows the operator to adjust the flow rate and maintain a steady flow.

Bladder pumps are regarded in the literature as one of the best groundwater sampling devices for a number of reasons: compressed air is used as the driving gas since it does not come into contact with the sample; almost the entire assembly can be made of inert material; depths in excess of $60 \mathrm{~m}$ can be sampled and many bladder pumps are designed to sample $50 \mathrm{~mm}$ wells; ease of disassembly allows cleaning and repair in the field; variable pumping rates are possible, allowing well purging and low flow rate sampling (Nielsen and Yeates (1985)). However, these pumps are often expensive, the need for an air compressor or 
compressed air tanks and a pump control make these pumps less portable than others and waters with high suspended solids may block the check valves necessitating removal of the pump. In addition, lifting sample from deep wells requires large amounts of gas.

Electric submersible pumps

These pumps consist of a sealed electric motor that drives a two-stage centrifugal pump with radial impellers. A partial vacuum is created as the impeller rotates and forces water up a discharge line by centrifugal force, water is then drawn into the impeller housing continuing the pumping action. A screened intake inhibits large particles from entering and blocking the pump and a built in thermal switch turns off the pump if a maximum operating temperature is exceeded. The most commonly used pump of this type is the Grundfos MP1, which is designed to be used in two inch diameter wells or greater. This pump is powered by a $220 \mathrm{~V}$ generator and run via an adjustable frequency converter that allows a high range speed adjustment of the pump. High flow rate sampling with pumps such as this has been shown to mobilise more colloidal particles than bladder pumps, thus increasing sample turbidity (Puls et al., 1992). Puls also draws attention to the disturbance caused to the water column from the insertion and removal of these pumps and recommends the use of dedicated samplers in each borehole.

Rosen et al. (1992) compared downhole sampling using a helical rotor type of centrifugal pump with an absorption cartridge for volatile organic compounds They found that this method of bringing water to the surface could be reliable in many circumstances but that care was needed with adsorption, cross contamination and out gassing.

Submersible centrifugal pumps are now available with integral packers that allow the screened interval of the well to be isolated from the stagnant column above, thus negating purging requirements and reducing sampling times and costs.

\section{Common materials used in sampling devices}

It is important that the equipment used for sample collection and the subsequent handling and storage of samples doesn't contribute to the contaminant load of the sample for example, by leaching organics. The following are common materials used in sampling equipment construction (after Canter et al., 1990):

- Teflon - advantages include: it is inert, has poor sorptive qualities and low leaching potential and can be rigid or flexible; disadvantages include: cost

- Stainless steel - easy to clean but expensive

- $\quad$ PVC - good chemical resistance (except chlorinated solvents, ketones, aldehydes) and good for inorganics, but may bias some organic compounds

- High Density Polyethylene (HDPE) - commonly used in sample containers but can absorb trace metals if the sample is not acidified

- Glass - essential for samples with organic contaminants

\section{AVOIDING CROSS-CONTAMINATION}

If it is impractical to dedicate a sampling device to a single well or disposable samplers are not suitable, it is imperative that the sampling device is properly cleaned between deployments to avoid crosscontamination of samples and boreholes. Decontamination is essential for microbiological, organic and pesticide sampling and recommended, but not as critical, for major ion analysis. Use of proprietary cleaners is recommended and the operator should clean inside and outside of the sampling device and the associated hose. All cleaning operations should be undertaken away from boreholes and preferably somewhere where the waste water can drain to a foul sewer. To verify that no residual contamination remains in the sampler, a sample of deionised water should be passed through after the cleaning operation and analysed for the contaminants of concern. Wells that are known to be highly contaminated should have dedicated sampling devices installed whenever possible. At the very least, it is useful to have separate sampling devices to differentiate between 'background' and 'contaminated' samples. Where known, 'background' samples and those that are least contaminated should be collected before those that are more likely to be heavily contaminated.

\section{WATER LEVEL MEASUREMENTS}

The level of the water in a well is measured to provide data for groundwater flow direction calculations and to calculate purge volumes required for a particular well. If a low flow sampling protocol is used, the water 
level is also measured during pumping to ensure that there is minimal drawdown of the stagnant water column.

The static water level (SWL) should be measured before purging, sampling or inserting any other device into the well. It is also good practice to collect water level measurements from all site wells within a reasonably short time, i.e. by measuring all water levels at the start of the day. This mitigates against measurements not being comparable to one another due to a heavy rainfall event overnight. Measurements should always be taken to a permanent reference point, e.g. the casing top. To minimise crosscontamination, the least contaminated wells should be measured first and the measuring device should be thoroughly cleaned before deployment in the next well.

Water level measurements should be compared to previous data to verify that previously calculated purge volumes remain valid prior to purging and sampling.

There are level measurement devices (dip meters) available as small as $6.4 \mathrm{~mm}$ in diameter to fit narrow diameter wells. In general the tape is marked every millimetre (although smaller diameter tapes are less frequently marked) and come in lengths of $30 \mathrm{~m}$ to $600 \mathrm{~m}$. A high-pitched alarm sounds when water is reached and the distance read from the tape. Dip meters can also be used to measure the total depth of a well and interface meters are available that measure immiscible product levels on top of the water column.

Automated water level measurement can be achieved by deploying pressure transducers that can be set to $\log$ data as frequently as every second if required. Loggers also record temperature and are able to compensate for altitude, water density, temperature and barometric pressure. These are routinely used when undertaking hydraulic tests on a well but are also useful to provide accurate, regular, long-term water level data and are invaluable for groundwater flow direction calculations.

\section{WELL PURGING TECHNIQUES}

Groundwater samples representative of in-situ conditions are difficult to obtain because of complex physical, chemical, geological and bacterial processes. Monitoring wells are often completed with screen lengths that are shorter than the column of water in the well. Water sitting above the screened interval is liable to stagnation as fresh water is unable to flow in this section of the well. In order to collect a sample that is representative of the water flowing through the geological formation, it is important to either remove the stagnant water or sample from the screened section of the well at a rate of flow equal to that flowing through it. Interaction of air in the well with the top of the column of water can change the chemical composition of the water. For example, the dissolved gas content (dissolved oxygen and carbon dioxide) of the water will equilibrate with the air column causing oxidation and precipitation of some metals (e.g. iron and manganese) out of solution. Biological activity, interaction with well casing material and material falling into the well will also affect the water quality. The most common way to mitigate against this is to remove the stagnant water prior to collecting the sample.

\section{Specified number of well volumes}

Traditionally the removal of stagnant water from a monitoring well is accomplished by purging a fixed number of well volumes, generally between three to five volumes, prior to sample collection. A well volume is defined as the amount of water in the well casing and screened portion of the well at static water level conditions and is calculated using the formula: Volume $=\pi r^{2} h$, where $r$ is the radius of the borehole and $h$ the height of the water column. However, this method does not take into account the annulus between the well casing and the true diameter of the drilled borehole, which is often backfilled with gravel. This annulus should also be taken into account when calculating well volumes and is calculated as the drilled borehole diameter minus the well casing volume multiplied by the porosity of the fill material. Submersible pumps are generally used when purging as high flow rates are required, although inertial pumps can be used, particularly where smaller purge volumes are required. One technique is to locate the pump above the screen so it can be lifted to the top of the water column to remove the stagnant water.

The 3-5 well volume purge approach has a number of disadvantages:

1. Large volumes of potentially contaminated waste water requiring off-site disposal are often produced. 
2. Turbidity is increased due to the high rate of pumping required to purge large volumes of water in a reasonable time frame.

3. Water from different zones in the aquifer is mixed giving an averaged concentration of contaminants in the well. Zones of interest will not be identified.

4. Volatile compounds may be lost due to agitation of the sample.

5. It is relatively easy to pump wells dry mistakenly, allowing aeration of sample that had previously existed in an anaerobic environment.

Another problem with this approach is the lack of scientific evidence to determine when a sample should be collected. This can be alleviated by monitoring water quality parameters such as $\mathrm{pH}$, temperature (t), electrical conductivity (EC), oxidation-reduction (or redox) potential (ORP, otherwise referred to as Eh) and dissolved oxygen $\left(\mathrm{DO}_{2}\right)$ throughout the purge to ascertain when the stagnant water has been removed. Plotting the stabilisation times of these parameters can inform the sampler when a sample can be collected. For subsequent sampling rounds, purge times can be related to parameter stabilisation times, hence reducing the purge time required. Many sampling practitioners use EC as the basis for stabilisation, but Puls and Powell (1992) report that $\mathrm{pH}, \mathrm{t}$ and $\mathrm{EC}$ are the least sensitive indicators of aquifer equilibration. Redox potential, $\mathrm{DO}_{2}$ and contaminant concentration were reported to be more sensitive, and turbidity the most sensitive indictor of equilibrated conditions. Therefore the general order of stabilisation is $\mathrm{pH}, \mathrm{t}, \mathrm{EC}$, Eh, $\mathrm{DO}_{2}$ and turbidity and samples should not be collected until at least dissolved oxygen concentration has stabilised. In-line flow cells are recommended to continually monitor these parameters to avoid contact of the sample with the atmosphere.

A study by Gibbs et al. (1990) found that monitoring field water-quality parameters for stability is not a reliable indicator of when to collect a representative sample for purgeable organic compounds (POCs), such as chlorinated alkanes, alkenes and aromatics. For these types of compounds, the researchers suggest direct monitoring of POC concentrations.

Re-evaluation of sampling techniques in recent years has led to researchers developing a new technique that reduces the amount of purge water by negating the need to remove the stagnant water column in a well. Controlled pumping of the well at low flow rates $(<500 \mathrm{~mL}$ per minute) while monitoring indicator parameters to the point of stabilisation has been shown to produce samples comparable with those collected using a full purge technique.

\section{Low-flow purging}

Water flowing through the screened interval of a monitoring well is representative of the formation water and chemically distinct from the overlying stagnant column (Robin and Gillham, 1987). The theory of low-flow purging (sometimes referred to as micropurging) takes advantage of this and aims to minimise the drawdown in a well during pumping by placing the pump across or just above the screened interval and pumping at a very slow rate. Low-flow refers to the velocity of the formation water entering the well screen. Low-flow purging effectively isolates the stagnant column of water as groundwater flows through the well screen at a sufficiently low velocity such that water is only taken from the screened interval thus leaving the stagnant water undisturbed.

Significant research into the flow patterns that occur in monitoring wells has been undertaken over the last 10-15 years and is summarised here.

Observations of colloidal movement under natural conditions and during pumping were conducted at several field sites by Kearl et al. (1992). Results indicated that the installation of dedicated sampling devices, limited purging of the well prior to sampling, sampling at a flow rate of $100 \mathrm{~mL}$ per minute, and not filtering samples may collectively improve the representativeness and cost effectiveness of obtaining groundwater samples for assessing the total mobile contaminant load.

Puls and Powell (1992) recommended the use of low-flow rates during both purging and sampling, placement of the sampling intake at the desired sampling point, minimal disturbance of the stagnant water column above the screened interval, monitoring of water quality indicators during purging, minimisation of atmospheric contact with samples, and collection of unfiltered samples for metal analyses to estimate total contaminant loading in the system. While additional time is often required to purge using low-flow rates, the authors state that this is compensated for by eliminating the need for filtration, decreased volume of 
contaminated purge water and less re-sampling to address inconsistent data results. The use of low-flow rate purging and sampling consistently produced filtered and unfiltered samples that showed no significant differences in concentrations.

A comparison of micropurging and traditional groundwater sampling was reported by Kearl et al. (1994). To compare methods, duplicate groundwater samples were collected at two field sites using traditional and micropurge methods. Samples were analysed for selected organic and inorganic constituents, and the results were compared statistically. Analysis of the data using the nonparametric sign test indicated that there was no significant difference (at 95 percent confidence) between the two methods for the site contaminants and the majority of analytes. These analytical results were supported by visual observations using a colloid borescope, which demonstrated impacts on the flow system in the well when using traditional sampling methods. Under selected circumstances, the results suggest replacing traditional sampling with micropurging based on reliability, cost and waste minimisation. The authors recommend that samples should be collected with dedicated sampling devices such as bladder or submersible pumps. Bailers should not be used, pump intakes should be located in the centre of screens unless depth specific samples are required and samples should be collected 24 hours after pump installation. In addition, only the pump and tubing should be purged, as they believe it is not necessary to purge the well casing and the screen.

Greacen and Slivia (1994) conducted a comparison of low-flow versus high-flow (borehole purge) sampling methodologies on groundwater metal concentrations. They found that although a submersible sampling pump provided an efficient means of collecting groundwater samples, the use of the low-flow sampling methodology did not provide data that could not be obtained by sampling the well at higher flow rates.

Research by Barcelona et al. (1994) confirmed that low-flow rate purging (i.e. 1 L per minute) is a valid technique for 2" $(5 \mathrm{~cm}$ ) diameter monitoring wells with short-screened intervals. They reported that the use of low-flow, and dedicated pumping devices for purging and sampling minimises both the disturbance of stagnant water in the well casing and the potential for mobilisation of particulate or colloidal matter that can lead to sampling artefacts. In addition, these techniques allow the use of purging indicator parameters (e.g. dissolved oxygen and electrical conductivity) to determine when to collect a sample for volatile organic compound (VOC) determinations. The suggested procedure includes documenting purging indicator parameters while purging with dedicated devices at low-flow rates with minimal drawdown. This sampling method is less time-consuming and reduces the need to handle large volumes of purge water since VOC concentrations, $\mathrm{DO}_{2}$ and specific conductance values stabilised consistently in less than one borehole volume.

An investigation of contaminant migration by low-flow rate sampling techniques by Bangsund et al. (1994) used low flow rates (10-100 mL per minute) to minimise drawdown and colloidal migration. Unfiltered samples collected using these methods are believed to be more representative of actual groundwater quality. Due to the nature of the contaminants, an all-stainless steel positive-displacement gas drive pump was used. Drawdown was monitored continuously during sampling. Redox potential, $\mathrm{pH}$, temperature, electrical conductivity, dissolved oxygen, and turbidity were monitored in the field to establish water quality stabilisation. Water quality in the wells stabilised after removal of one or two well volumes. Turbidity and ORP were found to be the best field indicators of water quality stabilisation during sampling. Results indicate that the unfiltered samples collected using the low flow sampling method have concentrations of inorganic parameters roughly equal to historic filtered sample results, and as much as three orders of magnitude lower than unfiltered sample results from standard sampling methods.

In 1995, Puls and Paul conducted a field study to assess purging requirements for dedicated sampling systems in conventional monitoring wells and for pumps encased in short screens and buried within a shallow sandy aquifer. Low-flow purging methods were used, and wells were purged until water quality indicator parameters (dissolved oxygen, electrical conductance, turbidity) and contaminant concentrations (chromate, trichloroethylene, dichloroethlyene) reached equilibrium. The data show that purge volumes were independent of well depth or casing volumes. Contaminant concentrations equilibrated in less than $7.5 \mathrm{~L}$ of purge volume in all wells. Initial contaminant concentration values were generally within 20 percent of final values. Water quality parameters equilibrated in less than $10 \mathrm{~L}$ in all wells and were conservative measures for indicating the presence of adjacent formation water. Water quality parameters 
equilibrated faster in dedicated sampling systems than in portable systems and initial turbidity levels were lower.

In 1996, Puls and Barcelona published a US EPA - Ground Water Issue to provide background information on the development of low flow sampling procedures and its application under a variety of hydrogeological settings.

Various physical and chemical properties were monitored sequentially by Gibs et al. (2000) during well purging as indicators of stabilisation of the water in the well. Turbidity was correlated with the concentrations of $\mathrm{Fe}, \mathrm{Al}$ and $\mathrm{Mn}$ in oxic groundwater, but appeared to be independent of conductivity, $\mathrm{pH}$, temperature or dissolved oxygen. $\mathrm{Pb}$ and $\mathrm{Cu}$ were related to the sum of the $\mathrm{Fe}, \mathrm{Al}$ and $\mathrm{Mn}$. Stabilisation of turbidity was found to be a good indicator of stable unfiltered trace element concentrations at all wells monitored and for some filtered trace element concentrations.

\section{'No purge' sampling}

'No purge' sampling (see earlier section on Passive Diffusion Bags, Snap Sampler and Hydrasleve) is becoming an increasingly accepted method of collecting representative groundwater samples for some determinands, in particular VOCs and some metals using diffusion methods. These sampling systems are deployed in the well and left to equilibrate with the formation water thus negating the need for purging. Double ended bailers can be classed as grab samplers but can also be used to purge shallow wells that have low volumes of water

\section{DEDICATED PUMP VERSUS PORTABLE SAMPLE COLLECTION}

Passing a sampling device through a stagnant column of water can cause mixing with the screened interval, disturbance to the suspended sediment at the bottom of the casing and displacement of water into the formation immediately adjacent to the well screen. This can be avoided by using dedicated pumps. This approach also minimises the potential for cross-contamination between boreholes when a common pump is used. In addition, it has been shown that water quality parameters equilibrate faster in dedicated sampling systems than in portable systems and initial turbidity levels tend to be lower (Puls and Powell, 1992).

\section{ON-SITE WATER QUALITY MEASUREMENTS}

On-site water quality measurements are carried out predominantly to monitor effective purging of water at the sampling point before sample collection, and to measure unstable parameters that cannot be subsequently reliably determined in the laboratory. On-site measurements can also be used to provide a check on a subsequent laboratory analysis. For example, provided that the on-site Specific Electrical Conductance (SEC) is measured accurately, it can be compared with the SEC estimated from the laboratory chemical analysis by one of a number of geochemical programmes. This check can be useful for spotting major errors, such as dilution or typographical errors, as well as systematic errors in analytical methodology.

A flow-through cell should be used for taking on-site chemistry measurements from a pumped sample. This is advised as it produces an airtight environment that isolates the flowing water to be sampled from the atmosphere. All air bubbles must be expelled from the cell to prevent anomalous readings and a constant flow must be maintained. All measurements need to be accurately recorded using a field data sheet or a notebook. Readings should be taken at regular intervals to monitor stabilisation before the final reported measurement is made.

\section{Temperature}

The rate of many biological and chemical reactions is affected by temperature, although deep groundwater temperatures are less susceptible to seasonal temperature fluctuations. Temperature should be recorded to 0.1 degree. Care is needed when making measurements since groundwater temperature can change quickly on exposure to ambient conditions and it is important to take the measurement as close as possible to the outlet and to exclude direct sunlight. Reporting of other on-site parameters should be corrected to the appropriate temperature. 
$\mathrm{pH}$ is a measure of the hydrogen ion concentration in solution and is also referred to as the degree of acidity or alkalinity. As a sample's $\mathrm{pH}$ changes, many precipitation, co-precipitation and sorption processes can occur that alter the sample's chemical composition and reaction rates. Biological processes of a sample are also influenced by its $\mathrm{pH}$. Changes in the dissolved gas content of a sample can alter the $\mathrm{pH}$. Groundwater is generally in equilibrium with $\mathrm{CO}_{2}$ at a partial pressure several times that of the atmosphere. On exposure to the atmosphere this $\mathrm{CO}_{2}$ escapes and the $\mathrm{pH}$ rises. It is therefore important that $\mathrm{pH}$ is measured on-site. The $\mathrm{pH}$ is generally measured using a combination electrode calibrated using standards of $\mathrm{pH}$ 4, 7and 10. In addition, it is recommended that a dilute acid solution of known $\mathrm{pH}$ is used as a control check and that additional control standards are also checked if the $\mathrm{pH}$ is outside the range 4-10.

\title{
Specific Electrical Conductance (SEC)
}

Specific electrical conductance (SEC) is the measure of a solution's ability to conduct or carry an electric current and depends upon the presence of charged ion species such as calcium, sodium, magnesium chloride, etc. Conductivity measurements are approximately related to total dissolved solids (TDS) in a sample, but since different ions carry different amounts of charge and move at different speeds, their individual contribution to the overall SEC varies.

SEC is measured with a conductivity meter, which normally consists of an AC bridge and a conductivity cell or electrodes. The conductance is measured between two electrodes. Two solutions of known conductivity should be used, one to calibrate the meter and the other to check the slope. It is important to correct all data for water temperature, either by calculation or automatically using the meter's autotemperature correction mode, since SEC is highly dependent on temperature. SEC increases by about $2 \%$ per degree rise in temperature due principally to an increase in water viscosity.

\begin{abstract}
Alkalinity
Alkalinity is a measure of the acid-neutralising capacity of water and is usually determined by titration against sulphuric acid to the endpoint of the acid-base reaction. In groundwaters, the carbonate species predominate and an endpoint of about pH 4.5 marks the consumption of bicarbonate in solution. The endpoint can be determined using an indicator dye, such as bromocresol green, or the $\mathrm{pH}$ can be monitored and the inflection of the titration curve identified. In relatively uncommon water where the $\mathrm{pH}$ is high, the titration curve may also indicate an inflection due to the presence of carbonate. In some waters, other weak acids, such as borate, silicate and organic acids may also contribute to the alkalinity.
\end{abstract}

Alkalinity measurements are often made on-site but are sometimes not considered to be as critical as $\mathrm{pH}$, since loss of $\mathrm{CO}_{2}$ does not in itself change the alkalinity. However, Shaver (1993) and Fritz (1994) found significant errors were introduced by use of laboratory rather than in-situ data. That said, it is possible for inexperienced samplers to mistakenly identify the end-point of the titration in the field, and it is always recommended that alkalinity is also determined back in the laboratory. During storage there may be biological activity that changes the alkalinity or extreme loss of $\mathrm{CO}_{2}$ may lead to precipitation of $\mathrm{CaCO}_{3}$ in the sample bottle. In carbonate terrains it may be necessary to filter the alkalinity sample as there may be suspended particles of calcite leading to an overestimate of the value (Fritz, 1994). For some highly contaminated samples, a stable endpoint may not be obtained if there is equilibration with a solid phase.

\section{Dissolved oxygen ( $\left.\mathrm{DO}_{2}\right)$}

Dissolved Oxygen $\left(\mathrm{DO}_{2}\right)$ levels in water depend, in part, on the chemical, physical and biochemical activities occurring in the water. Oxygen has a limited solubility in water directly related to atmospheric pressure and inversely related to water temperature and salinity. Low dissolved oxygen levels can limit the bacterial metabolism of certain organic compounds.

On-site, dissolved oxygen is commonly measured using a membrane electrode of the polarographic type in a flow-through cell. The zero is commonly set using a saturated solution of sodium sulphite and the $100 \%$ saturated environment by holding the probe close to the surface of clean water. Below $1 \mathrm{ppm}$, electrodes provide only a qualitative measure of $\mathrm{DO}_{2}$ due to slow electrode response (Wilkin et al., 2001).

\section{Oxidation-reduction potential (ORP)}

Reduction-oxidation reactions are mediated by micro-organisms and involve the transfer of electrons between reactant and products. Free electrons do not exist in solution, so an oxidation reaction (loss of 
electrons) must be balanced by a reduction reaction (gain of electrons). Redox potential is defined by the

Nernst

the

Redox

the

ions in

which

of

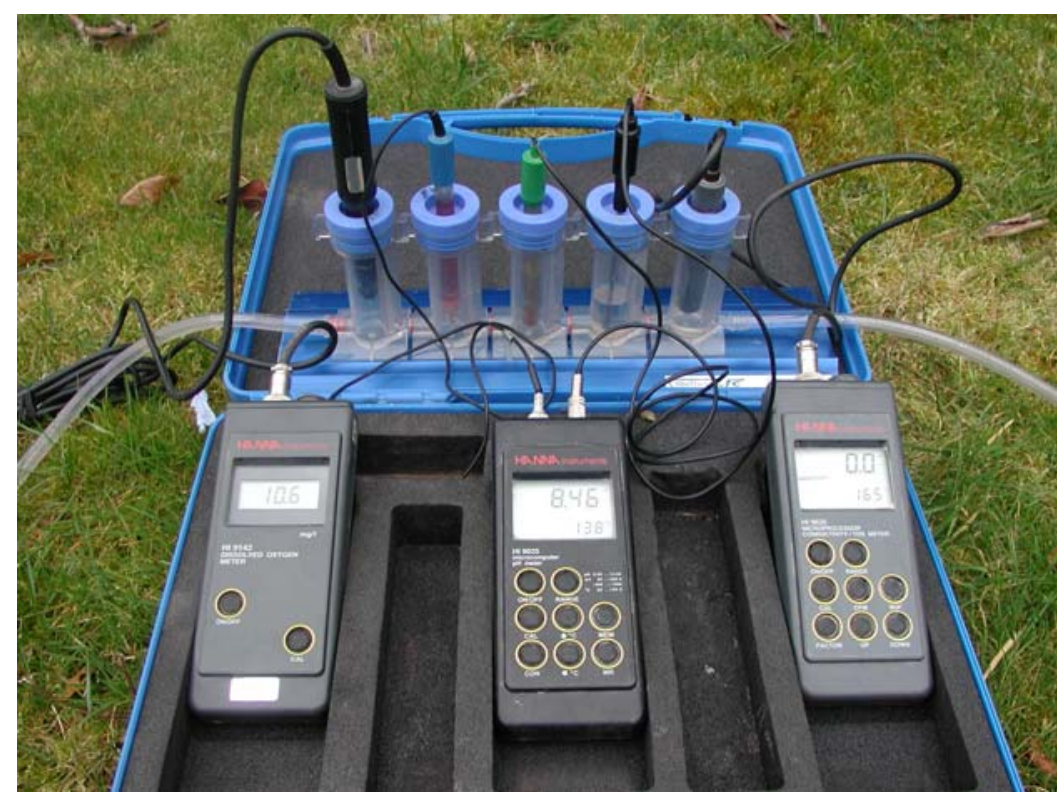

equation and is the energy gained in transfer of $1 \mathrm{~mol}$ of electrons from an oxidant to $\mathrm{H}_{2}$.

reactions control mobility of metal solution by changing the valence state, in turn changes the solubility of metals causing them to dissolve into or precipitate out of solution; a common example is the reduction/oxidation iron:

$\mathrm{Fe}^{3+}+\mathrm{e}^{-}=\mathrm{Fe}^{2+}$ reduction (dissolved in solution)

$\mathrm{Fe}^{2+}=\mathrm{Fe}^{3+}+\mathrm{e}^{-}$oxidation (precipitates out of solution)

ORP is measured on-site by monitoring the potential developed at a platinum surface under in-situ conditions in a flow-through cell. In the presence of oxygen the electrode behaves as a Pt-O electrode and responds predominantly to $\mathrm{pH}$; consequently the measurement of ORP in oxygenated waters does not yield much useful information. In reducing waters, the measured potential will be a mixture of potentials developed from a range of redox reactions often involving iron, sulphur and nitrogen species. The redox electrode cannot be calibrated, but correct function can be checked by measuring temperature and the $\mathrm{mV}$ obtained from Zobell's solution and comparing the temperature-corrected reading with tabulated results (see manufacturer's information and Nordstrom (1977).

ORP measurements are effective in delineating oxic from anoxic groundwater, but ORP measurements cannot distinguish between nitrate-reducing, Fe (III)-reducing, sulfate-reducing or methanogenic zones in an aquifer.

Figure 2 On-site Water Quality Measurements Using a Flow-Through Cell 


\section{PRESERVATION AND HANDLING OF SAMPLES}

Waters are susceptible to change by differing extents as a result of physical, chemical or biological reactions that take place between the time of sampling and analysis. If suitable precautions are not taken before and during transport as well as the time spent in the laboratory, the nature and rate of these reactions are often such that concentrations determined will be different from those existing at the time of sampling. The causes of variation may include:

- Consumption or modification of constituents by micro organisms

- Photodegradation

- Oxidation by dissolved oxygen

- Precipitation

- Volatilisation

- Degassing

- Absorption of $\mathrm{CO}_{2}$ from the air

- Sorption of dissolved or colloidal phases to container walls

A summary of the preservation options and recommended maximum storage periods for various determinands is given in Table 1. The individual options are described below.

\section{Filtration}

The process of drilling, constructing, purging and sampling a well can mobilise colloids (particles ranging in size from $1 \mathrm{~nm}$ to $1000 \mathrm{~nm}$ ) and particulates that are not moving through the groundwater under natural flow conditions resulting in artificially high concentrations of inorganic constituents. These can be removed by filtration, which should be carried out on-site as soon as possible after collection. Standard filters for groundwater investigations are $0.45 \mu \mathrm{m}$ cellulose membranes. These do not remove all particulates from the sample or colloidal material of biological and non-biological origin in the 0.1-0.001 $\mu \mathrm{m}$ range. Filtration should not be used if the filter is likely to retain one or more of the constituents to be analysed. Different brands may not be identical in performance (Hall et al., 1996)

High turbidity samples can clog filters reducing the effective pore size. To avoid this, glass fibre pre-filters should be used and clogged filters changed regularly.

It is essential that the filter is not a cause of contamination and, if applicable, filters should be carefully washed before use. If possible a portion of sample should be flushed through the filter before sample collection. In general, samples for most organic determinands should NOT be filtered; highly turbid samples and all samples collected for dissolved metals SHOULD be filtered.

\section{Addition of preservatives}

The most commonly used preservatives for groundwater samples are:

- Acids 
- Bases

- Biocides

- Specialised reagents, e.g. for mercury or sulphides

Acidification to below $\mathrm{pH} 2$ is particularly suitable for trace metals since it minimises adsorption of metals to container walls and also reduces biological activity. Acidification prior to filtration will release metals bound to particulates giving a false reading if only dissolved metals are required. Samples for anion analysis are generally not acidified. Biocides such as sodium azide are commonly added to samples for trace organic compounds, such as pesticides. The use of $0.45 \mu \mathrm{m}$ silver filters for dissolved organic carbon samples both removes particulates and introduces silver into solution, which acts as a biocide.

Recommended techniques for preservation of waters are given in Table 1. It should be noted, however, that preservation techniques are often governed by the analytical method to be used; hence advice should always be sought from the laboratory on the type of bottle and preservation method required for each determinand.

Table 1 Techniques for the preservation of samples for analysis (simplified from BSI, 1996)

\begin{tabular}{|c|c|c|c|c|c|c|}
\hline Group & $\begin{array}{l}\text { Examples of } \\
\text { determinands }\end{array}$ & Container & Filtration & Preservation & $\begin{array}{l}\text { Cool to } \\
2-5^{\circ} \mathrm{C} \\
\text { for } \\
\text { storage }\end{array}$ & $\begin{array}{l}\text { Maximum } \\
\text { storage } \\
\text { time }\end{array}$ \\
\hline Total metals & $\begin{array}{l}\mathrm{Al}, \mathrm{Cr}, \mathrm{Co}, \mathrm{Cu}, \mathrm{Fe}, \mathrm{Pb}, \\
\mathrm{Mn}, \mathrm{Ni}, \mathrm{Ag}, \mathrm{U}, \mathrm{Zn}\end{array}$ & Plastic & - & $\begin{array}{l}\text { Acidify to }<\mathrm{pH} 2 \text { with } \\
\mathrm{HNO}_{3}\end{array}$ & $\checkmark$ & 1 month \\
\hline $\begin{array}{l}\text { Cations and } \\
\text { dissolved } \\
\text { metals }\end{array}$ & $\begin{array}{l}\mathrm{Al}, \mathrm{Cd}, \mathrm{Co}, \mathrm{Cu}, \mathrm{Fe}, \mathrm{Pb}, \mathrm{Li} \text {, } \\
\mathrm{Mn}, \mathrm{Ni}, \mathrm{Ag}, \mathrm{Ca}, \mathrm{Mg}, \mathrm{Na}, \\
\text { K, U, Zn, Sb, B, etc }\end{array}$ & Plastic & $\begin{array}{l}0.45 \mu \mathrm{m} \\
\text { cellulose }\end{array}$ & $\begin{array}{l}\text { Acidify to }<\mathrm{pH} 2 \text { with } \\
\mathrm{HNO}_{3}\end{array}$ & $\checkmark$ & 1 month \\
\hline $\begin{array}{l}\text { Redox } \\
\text { sensitive } \\
\text { cations }\end{array}$ & $\mathrm{Fe}^{2+}, \mathrm{NH}_{4}^{+}$ & Plastic & - & $\begin{array}{l}\text { Acidify to }<\mathrm{pH} 2 \text { and } \\
\text { exclude oxygen for } \\
\text { reduced species }\end{array}$ & $\checkmark$ & 24 hours \\
\hline Anions & $\begin{array}{l}\mathrm{Br}, \mathrm{Cl}, \mathrm{F}^{\ddagger}, \mathrm{NO}_{3}, \mathrm{o}-\mathrm{PO} 4, \mathrm{P}, \\
\mathrm{SO}_{4}^{2-*}, \mathrm{I}, \mathrm{B} \mathrm{SiO}_{4}^{*}\end{array}$ & Plastic & $\begin{array}{l}0.45 \mu \mathrm{m} \\
\text { cellulose }\end{array}$ & - & $\checkmark$ & 1 month \\
\hline $\begin{array}{l}\text { Redox } \\
\text { sensitive } \\
\text { anions }\end{array}$ & $\mathrm{NO}_{2}^{-} \mathrm{Cr}^{6+}$ species, $\mathrm{CN}^{-}$ & Plastic & - & $\begin{array}{l}\text { Exclude oxygen for } \\
\text { reduced species }\end{array}$ & $\checkmark$ & 24 hours \\
\hline $\begin{array}{l}\text { Sulphur } \\
\text { species }\end{array}$ & $\mathrm{S}^{2-}, \mathrm{SO}_{2}^{2-}$ & Plastic & - & $\begin{array}{l}\text { Fix by alkalization or } \\
\text { EDTA as required }\end{array}$ & $\checkmark$ & 24 hours \\
\hline $\begin{array}{l}\text { Anionic } \\
\text { metals }\end{array}$ & As, Se, Sn & Plastic & - & Acidify to $<\mathrm{pH} 1$ with $\mathrm{HCl}$ & $\checkmark$ & 1 month \\
\hline Total anions & $\mathrm{o}-\mathrm{PO}_{4}, \mathrm{P}, \mathrm{N}$ & Plastic & - & $\begin{array}{l}\text { Acidify to }<\mathrm{pH} 2 \text { with } \\
\mathrm{H}_{2} \mathrm{SO}_{4}\end{array}$ & $\checkmark$ & 24 hours \\
\hline $\begin{array}{l}\text { Volatile } \\
\text { inorganics }\end{array}$ & $\mathrm{Hg}$ & $\begin{array}{l}\text { Borosilicate } \\
\text { glass }\end{array}$ & & $\begin{array}{l}\text { Acidify to }<\mathrm{pH} 2 \text { with } \\
\mathrm{HNO}_{3} \text { and add } \mathrm{K}_{2} \mathrm{Cr}_{2} \mathrm{O}_{7} \text { to } \\
0.05 \%\end{array}$ & $\checkmark$ & \\
\hline $\begin{array}{l}\text { Oxygen } \\
\text { demand }\end{array}$ & BOD, COD & Glass & - & Exclude light & $\checkmark$ & 24 hours \\
\hline Stable isotopes & ${ }^{2} \mathrm{H},{ }^{18} \mathrm{O},{ }^{13} \mathrm{C}$ & Glass & - & - & - & \\
\hline $\begin{array}{l}\text { Dissolved } \\
\text { gases }\end{array}$ & $\mathrm{N}_{2}, \mathrm{Ar}, \mathrm{CH}_{4}$ & $\begin{array}{l}\text { Glass or steel } \\
\text { pressure } \\
\text { vessel }\end{array}$ & & & - & \\
\hline Fluorocarbons & CFCs, $\mathrm{SF}_{6}$ & $\begin{array}{l}\text { Specialised } \\
\text { container }\end{array}$ & & & - & \\
\hline Volatile & Chlorinated solvents, light & Glass with & - & Exclude light & $\checkmark$ & 7 days \\
\hline
\end{tabular}




\begin{tabular}{|l|l|l|l|l|l|l|}
\hline organics & hydrocarbons & septum cap & & & & \\
\hline $\begin{array}{l}\text { Non-volatile } \\
\text { organics }\end{array}$ & $\begin{array}{l}\text { Grease, oil, pesticides, } \\
\text { phenols, PAH }\end{array}$ & Glass & - & $\begin{array}{l}\text { Addition of biocide for } \\
\text { some determinands, } \\
\text { Exclude light }\end{array}$ & $\checkmark$ & 7 days \\
\hline Surfactants, & $\begin{array}{l}\text { Anionic, non-ionic } \\
\text { cationic }\end{array}$ & Glass & - & Varies with type & $\checkmark$ & 7 days \\
\hline $\begin{array}{l}\text { Organic } \\
\text { carbon }\end{array}$ & Total /dissolved & Glass & $\begin{array}{l}0.45 \mu \mathrm{m} \\
\text { silver for } \\
\text { dissolved }\end{array}$ & Exclude light & $\checkmark$ & \\
\hline Microbiology & & $\begin{array}{l}\text { Glass or heat } \\
\text { resistant } \\
\text { plastic }\end{array}$ & & & & \\
\hline
\end{tabular}

* can be included in cations if total element is required by ICP-OES

${ }^{\ddagger}$ not PTFE

\section{Solvent extraction}

Solvent extraction used for organic analysis is not a feasible field operation and therefore samples should be stored at $4^{\circ} \mathrm{C}$ and transported to the laboratory as soon as possible. The use of opaque or brown glass containers can reduce the photosensitivity of the sample to a considerable extent.

\section{Cooling or freezing}

The sample should be kept at a temperature lower than that at which it was collected. Cooling is only effective if it is applied immediately after the collection of the sample. This normally requires the use of a cool box containing ice or a refrigerator in the vehicle. Cooling is particularly important for minimising microbial activity. In some cases samples can be frozen. The freezing and thawing must be controlled in order to return the sample to its initial equilibrium after thawing. Glass containers are not suitable for samples that are to be frozen.

\section{Sample containers}

It is essential that the sample container and its cap should not be a cause of contamination, or absorb or react with constituents to be determined in the sample. For many inorganic determinands, modern plastic containers such as LDPE are probably the best option.

It is advised that sample bottles are soaked in a 1 molar solution of the preservative acid and thoroughly rinsed in high grade deionised or distilled water. For phosphate, silicon, boron and surfactants, detergents should not be used for cleaning purposes. For pesticides and their residues, containers should be cleaned with water and detergent followed by thorough rinsing with high grade water, oven drying at $105^{\circ} \mathrm{C}$ and rinsing with the solvent to be used during the analysis. For TOC/DOC the use of carefully cleaned containers using chromic acid or a specialised surfactant is essential. For microbiological analyses, the container must be able to withstand sterilisation procedures.

In general it is advisable to fill the container as completely as possible to minimise interaction with the gas phase and consequent changes in carbon dioxide content and $\mathrm{pH}$. Where samples are to be acidified, sufficient space must be allowed for in the container. For trace volatile organics that are not to be extracted on-site, it is absolutely essential to fill the container completely so that no air bubbles are seen when the container is inverted to minimise partitioning of the volatiles into the gas phase. For microbiological examination, an air space should be left so the sample container should not be filled to the brim. This aids in mixing before examination and avoidance of accidental contamination.

Where sufficient volume is available, all containers and caps should be rinsed several times with sample before collecting the sample. 


\section{QUALITY ASSURANCE AND QUALITY CONTROL PROCEDURES}

It is important that sample integrity be maintained and guaranteed throughout the collection, transport and analytical processes; this can be achieved by including strict QA/QC procedures in the sampling protocol. The areas that should be considered are:

\section{Blank samples}

Blanks consist of deionised water that is carried through all or part of the sampling and analytical processes to provide an indication of contamination. Types of blank sample include both laboratory and field blanks, listed below in ascending order of cumulative potential contamination.

\section{Laboratory blanks}

Instrument blank - a blank analysed with field samples to assess the presence or absence of instrument contamination.

Method blank - an analytical control consisting of all reagents, internal standards and surrogate standards, which is carried through the entire analytical procedure. The method blank is used to define the level of laboratory background and reagent contamination.

\section{Field blanks}

Trip blanks - a clean sample that is sent from the laboratory with the empty sampling bottles and remains with other samples throughout the sampling trip without being opened. This is typically only required for volatiles and assesses contamination during shipping and field handling.

Field blanks - field blanks are performed by passing a volume of contaminant-free water through all processing equipment that an environmental sample would contact including filtration, addition of preservative, transfer to the sample container in the field, and shipping to the laboratory with field samples. The results of field blanks can be used to assess contamination issues associated with processing and transporting the sample.

Equipment blanks - a sample of contaminant-free water poured through decontaminated field sampling equipment prior to the collection of field samples. For pump blanks, two blanks may be taken: one before the pump is cleaned and one after. A sample of the water used to pass through the pump should also be collected. These samples should be taken at the beginning and end of each day's sampling. These blanks assess the adequacy of the decontamination process and also assess the total contamination from sampling sample preparation and measurement processes.

\section{Replicate samples}

Replicate samples should be collected at the same time (preferably a split of one sample rather than by collecting two or more concurrent samples in the field) and undergo the same filtration, preservation and storage. These replicate samples measure the variability of the processing techniques and the laboratory precision, but exclude field-sampling variability.

\section{Spiked samples}

Field matrix spikes can be carried out by adding a known amount of a spike solution with a known concentration to a replicate sample. Spike recoveries can be used to identify which compounds are consistently under or over reported or which compounds are variable in their recoveries. This is particularly relevant to the analysis of organic contaminants.

\section{Labelling}

Containers should be labelled in a clear and durable manner to permit identification without ambiguity in the laboratory. Sample labels should adhere firmly to bottles. Sample lists should be provided to the laboratory.

\section{Transport}

It is important that the samples are transported quickly, safely and securely from field to laboratory. In particular, care must be taken to ensure that bottles are protected from breakage (particularly glass bottles) and loss of sample and that they are held at the required temperature. 


\section{Laboratory reception}

On arrival at the laboratory, the samples should be preserved under conditions that minimise any contamination of the outside of the containers and that prevent any change in their content.

\section{Chain of custody}

Chain of custody paperwork should be completed and copies retained. A chain of custody is a set of procedures used to provide an accurate written record that can be used to trace the possession of a sample from the moment of its collection through its introduction into a data set. Sample identity is maintained by proper labelling. Each person involved in the chain of possession must sign a chain-of-custody form when sample custody is relinquished or received.

A chain-of-custody form is a document used to record the transfer, possession, and custody of samples and to ensure the integrity of samples from the time of collection through data reporting. The chain-of-custody form should, at a minimum, contain the following information:

- Contact name and address of sampler

- $\quad$ Signature of sampler

- $\quad$ Order/batch number

- $\quad$ Sample id

- Sample location

- Date

- $\quad$ Time

- $\quad$ Sample type

- Number of containers

- Details of analysis required

- Dispatcher signature and date/time

- Courier signature and date/time

- Laboratory receipt signature and date/time

\section{DATA VALIDATION}

There are a number of relatively simple tests that can be employed to evaluate the analytical data and to check for possible transcription or dilution errors, changes during storage or unusual or unlikely values. A discussion of these can be found in Hem (1985) and Cook et al. (1989), among others.

\section{Comparison of field and laboratory values}

The comparison of field and laboratory determined results for parameters such as alkalinity and SEC can be indicative of:

- $\quad$ Sample confusion, e.g. errors arising from mislabelling

- $\quad$ Sample storage problems

\section{Comparison with other samples from the same source}

A simple screening procedure for evaluating analyses from the same or similar sources is to compare the results with one another. Transcription or dilution errors become readily evident.

\section{Comparison with other samples from the area}

A table of minimum and maximum values is helpful for identifying unusually low or high values. The data should be evaluated for a consistent pattern of highs and lows and anticipated correlations.

\section{Comparison of SEC and TDS}

An approximate accuracy check is possible using the SEC and TDS determinations. The TDS (in $\mathrm{mg} \mathrm{L}^{-1}$ ) should be between 0.55 and 0.75 times the SEC (in $\mu \mathrm{S} / \mathrm{cm}$ ) for most waters up to a TDS of a few thousand $\mathrm{mg} \mathrm{L.}{ }^{-1}$. Water in which anions are mostly dominated by bicarbonate and chloride should have a factor 
near the lower end of this range whereas waters high in sulphate may reach or even exceed the upper end. For repeated analyses from the same area, a well-defined relationship can often be established.

\section{Evaluation of charge balance errors}

The quality of chemical analyses can be checked on the basis of an ionic charge balance. This check should be carried out as soon as possible, while the chemical analysis can still be repeated. The ion balance can only be calculated for samples that have complete chemical analyses. The main purpose is to detect obvious errors and bias in the analysis but it will only detect these in the major species. Some errors may cancel each other out and this check does not provide confidence in major uncharged species, such as silica, or trace elements. The effect on the balance of minor components, e.g. phosphates and organic acids, which are not always included in the analysis, is usually negligible. Bicarbonate ions dissociate into carbonate ions, but this is negligible below $\mathrm{pH}=8$. For neutral groundwater the charge balance $(C B)$ is calculated as the total cation charge minus the total anion charge divided by the total charge in solution all expressed in microequivalents per litre:

$$
\mathrm{CB}=\frac{100(\mathrm{Na}+\mathrm{K}+\mathrm{Ca}+\mathrm{Mg})-\left(\mathrm{HCO}_{3}+\mathrm{Cl}+\mathrm{SO}_{4}+\mathrm{NO}_{3}\right)}{\left(\mathrm{Na}+\mathrm{K}+\mathrm{Ca}+\mathrm{Mg}+\mathrm{HCO}_{3}+\mathrm{Cl}+\mathrm{SO}_{4}+\mathrm{NO}_{3}\right)}
$$

For very alkaline waters it may be necessary to include other species such as carbonate or silicate ions. Acid water will contain $\mathrm{H}^{+}$ions, but water with a $\mathrm{pH}$ of less than 4.5 may not provide a usable acidity due to interference from other species such as some iron hydroxides.

As a general guideline, based upon the difference and the sum of cation and anion concentrations, the percentage ionic charge balance should be lower than $\pm 5 \%$, except for samples with low TDS.

There are some instances where the charge balance may not detect errors:

- Waters with a TDS of greater than $1000 \mathrm{mg} \mathrm{L}^{-1}$ tend to have large concentrations of a few constituents and the charge balance does not adequately evaluate the accuracy of the values of the minor constituents.

- Solutions that are strongly coloured may contain organic anions at sufficiently large concentrations to prevent a satisfactory balance being obtained.

- Waters of low ionic strength (generally cation or anion totals $<1 \mathrm{mg} \mathrm{L}^{-1}$ ) in which determinands may be close to or less than the limit of quantification.

\section{Comparison of measured and calculated TDS (or measured and calculated SEC)}

Assuming that the TDS or SEC is measured accurately, it can provide a check on the subsequent chemical analysis. This check is useful for spotting major errors, such as dilution or typographical errors as well as systematic errors in analytical methodology. It does not provide a check on any minor species or, in the case of SEC, uncharged species such as silica. Exactly which major species are present in any given water sample will depend on the type of water considered; Table 2 provides some guidance for calculating SEC.

$S E C=\sum C . F$

where $C$ is concentration in equivalents and $F$ is ionic conductance.

Table 2 Ionic conductance at infinite solution and $25^{\circ} \mathrm{C}$ for different aqueous species (MacInnes 1939)

\begin{tabular}{|l|l|l|}
\hline Species & $\begin{array}{l}\text { Equivalent ionic conductance } \\
\text { (S.cm } / \mathbf{e q})\end{array}$ & Use \\
\hline Acetate & 40.9 & Polluted waters \\
\hline $\mathrm{Ba}^{2+}$ & 63.6 & Where significant \\
\hline $\mathrm{Br}^{-}$ & 78.4 & Where significant \\
\hline
\end{tabular}




\begin{tabular}{|l|l|l|}
\hline $\mathrm{Ca}^{2+}$ & 59.5 & Routine \\
\hline $\mathrm{Cl}^{-}$ & 76.3 & Routine \\
\hline $\mathrm{F}^{-}$ & 55.4 & Where significant \\
\hline $\mathrm{H}^{+}$ & 349.7 & Acid rain and waters below $\mathrm{pH} 5$ \\
\hline $\mathrm{HCO}_{3}{ }^{-}$ & 44.5 & Routine \\
\hline $\mathrm{I}^{-}$ & 76.8 & Where significant \\
\hline $\mathrm{K}^{+}$ & 73.5 & Routine \\
\hline $\mathrm{Li}^{+}$ & 38.7 & Where significant \\
\hline $\mathrm{Mg}^{2+}$ & 53.0 & Routine \\
\hline $\mathrm{Na}^{+}$ & 50.1 & Routine \\
\hline $\mathrm{NH}_{4}{ }^{+}-\mathrm{N}$ & 73.5 & Polluted waters \\
\hline $\mathrm{NO}_{3}{ }^{-} \mathrm{N}$ & 71.4 & Routine \\
\hline $\mathrm{OH}^{-}$ & 198.0 & Waters above pH12 \\
\hline $\mathrm{Other}^{-}$organic anions & Varies & Some brown coloured waters \\
\hline $\mathrm{SO}_{4}{ }^{2}-\mathrm{S}$ & 79.8 & Routine \\
\hline $\mathrm{Sr}^{2+}$ & 59.5 & Where significant \\
\hline
\end{tabular}

\section{Apparent anomalies and impossibilities}

Species reported should be correct with regard to the original $\mathrm{pH}$ of the sample. At a neutral $\mathrm{pH}$, carbonate species will be almost all $\mathrm{HCO}_{3}$ and high $\mathrm{CO}_{3}$ cannot exist.

High Fe concentrations can be a problem to interpret since under oxidising conditions all Fe would be expected to be present as a highly insoluble Fe oxide. If high concentrations of iron are found then either the water must be reducing or some iron has passed the filter; this also applies for Al. Other possible anomalies to monitor data for are:

- Incompatible combinations of species, e.g. nitrate in presence of $\mathrm{Fe}^{2+}$ or the absence of dissolved oxygen

- Totals of any variable less than the sum of the component parts, e.g. total iron less than dissolved iron.

- Reported results not in the range of the technique or not theoretically possible, e.g. $\mathrm{pH}>14$

- Apparent zero concentrations for major ions, such as Na or Ca. A zero concentration is rare if these elements have actually been determined.

- Unusual parameter ratios, e.g. $\mathrm{Ca} / \mathrm{Mg}$ or $\mathrm{Na} / \mathrm{Cl}$. For example, groups of analyses where all magnesium concentrations are similar but calcium concentrations have a wide range may indicate that calcium and bicarbonate were lost during sampling or storage.

\section{HEALTH AND SAFETY IN FIELDWORK}

In all aspects of site investigations, health and safety considerations should take priority. Staff should be suitably trained and adequately supervised. Particular care should be taken with monitoring locations that pose particular difficulties for access or that are unsafe in any other way. Risk assessments should be prepared in advance and reviewed at regular intervals. Suitable personal protective equipment and emergency equipment and protocols should be available.

\section{REFERENCES}

Bangsund, W J, Peng, C G and Mattsfield, W R. 1994. Investigation of contaminant migration by lowflow rate sampling techniques. The Eighth National Outdoor Action Conference and Exposition, Minneapolis Convention Center, Minneapolis, Minnesota. 
Barcelona, M J, Helfrich, J A, Garske, E E and Gibb, J P. 1984. A Laboratory Evaluation of Ground Water Sampling Mechanisms. Ground Water Monitoring Review, Vol. 4, No. 2, 32-41.

Barcelona, M J, Helfrich, J A and Garske, E E. 1985. Sampling tubing on groundwater samples.

Analytical Chemistry, Vol. 57, 460-64.

Barcelona, M J, Wehrmann, H A and Varljen, M D. 1994. Reproducible well-purging procedures and VOC stabilization criteria for ground-water sampling. Ground Water, Vol. 32, No.1, 12-22.

Barker, J F and Dickhout, R. 1988. Evaluation of Some Systems for Sampling Gas-Charged Ground Water for Volatile Organic Analysis. Ground Water Monitoring Review Vol. 8, No. 4, 112-120.

BSI. 1996. Water quality. Sampling Part 3. Guidance on the preservation and handling of samples. BS EN ISO 5667-3.

Canter, L W, Knox, R C and Fairchild, D M. 1990. Ground water quality protection, (CRC Press) ISBN 0873710185.

Cook, J M, Edmunds, W M, Kinniburgh, D K and Lloyd, B. 1989. Field techniques in groundwater quality investigations. British Geological Survey Technical Report WD/89/56.

Fritz, S J. 1994. A survey of charge-balance errors on published analyses of potable ground and surface waters. Ground Water Vol. 32, No. 4, 539-546.

Gibs, J, Imbrigiotta, T E and Turner, K. 1990. Bibliography on sampling ground water for organic compounds. USGS Open File Report, 90-564.

Gibs, J, Szabo, Z, Ivahnenko, T and Wilde, F D. 2000. Change in field turbidity and trace element concentrations during well purging. Ground Water, Vol 38, No 4, 577-588.

Greacen, J and Slivia, K. 1994. A comparison of low flow vs high flow sampling methodologies on groundwater metals concentrations. The Eighth National Outdoor Action Conference and Exposition, Minneapolis Convention Center, Minneapolis, Minnesota.

Hall, G E M, Bonham-Carter, G F, Horowitz, A J, Lum, K, Lemieux, C, Quemerais, B and Garbarino, J.R. 1996. The effect of using different $0.45 \mu \mathrm{m}$ filter membranes on 'dissolved' element concentrations in natural waters. Applied Geochemistry, Vol 11, 243-249.

Hem, J D. 1985. Study and interpretation of the chemical characteristics of natural water. United States Geological Survey Water-Supply Paper 2254.

Kearl, P M, Korte, N E and Cronk, T A. 1992. Suggested modifications to ground water sampling procedure based on observations from the colloidal borescope. Ground Water Monitoring Review, Vol. 12, No.2, 155-61.

Kearl, P M, Korte, N E, Stites, M and Baker, J. 1994. Field comparison micropurging vs. traditional ground water sampling. Groundwater Monitoring \& Remediation, Vol.14, No. 4, 183-190.

MacInnes, D. 1939. Principles of Electrochemistry. Reinhold Publishing Corp, New York.

Nielsen, D M and Yeates, G L. 1985. A comparison of sampling mechanisms available for small-diameter ground water monitoring wells. Ground Water Monitoring Review, Vol. 5, No. 2, 83-99.

Nordstrom, D K. 1977. Thermodynamic redox equilibria of Zobell's solution. Geochimica et Cosmochimica Acta, Vol 41, No 12, 1835-1841.

Parker, L V. 1994. The effects of ground water sampling devices on water quality: A literature review. Groundwater Monitoring \& Remediation, Vol. 14, No. 2, 130-141.

Parker, L V and Clark, C H. 2002. Study of five discrete interval type groundwater sampling devices. US Army Corps of Engineers Technical Report, ERDC/CRREL TR-02-12.

Pearsall, K A and Eckhardt, D A V. 1987. Effects of selected sampling equipment and procedures on the concenrations of trichloroethylene and related compounds in ground water samples. Ground Water Monitoring Review, Vol. 7, No. 2, 64-73.

Pohlmann, K F and Hess, J W. 1988. Generalised ground water sampling device matrix. Ground Water Monitoring Review, Vol. 8, No. 4, 82-84.

Puls, R W, Clark, D A and Bledsoe, B. 1992. Metals in ground water: Sampling artifacts and reproducibility. Hazardous Waste \& Hazardous Materials, Vol. 9, No. 2.

Puls, R W and Powell, R M. 1992. Acquisition of representative ground water quality samples for metals. Ground Water Monitoring Review, Vol. 12, No.3, 167-176.

Puls, R W and Paul, C J. 1995. Low-flow purging and sampling of ground water monitoring wells with dedicated systems. Groundwater Monitoring \& Remediation, Vol. 15, No. 1, 116-123.

Puls, R W and. Barcelona, M J. 1996. Low-flow (minimal drawdown) ground-water sampling procedures. US EPA - Ground Water Issue.

Rannie, E H and Nadon, R L. 1988. Inexpensive, multi-use, dedicated pump for groundwater monitoring wells. Ground Water Monitoring Review, Vol. 8, No. 4, 100-107. 
Robin, M J L and Gillham, R W. 1987. Field evaluation of well purging procedures. Ground Water Monitoring Review, Vol. 7, No.4, 85-93.

Rosen, M E, Pankow, J F, Gibs, J and Imbrigiotta, T E. 1992. Comparison of downhole and surface sampling for the determination of volatile organic compounds (VOCs) in groundwater. Ground Water Monitoring Review, Vol 12, No 1, 126-133.

Shaver, R B. 1993. Field vs lab alkalinity and pH: effects on ion balance and calcite saturation. Groundwater Monitoring \& Remediation, Vol. 13, No. 2, 104-112.

Schuller, R, Gibb, J P and Griffin R. 1981. Recommended sampling procedures for monitoring wells. Ground Water Monitoring Review, Vol. 1, No. 2, 42-46.

Sladky, B and Roberts, P G. 2002. Zero-Purge Groundwater Sampling For Semivolatile Organic Compounds. ITRC - Diffusion Sampler Database.Available from http://www.diffusionsampler.org/ Stuart, A. 1984. Borehole sampling techniques in groundwater pollution studies. British Geological Survey Technical Report, WE/FL/84/15.

Wilkin, R T, McNeil, M S, Adair, C J and Wilson, J T. 2001. Field measurement of dissolved oxygen: a comparison of methods. Ground Water Monitoring and Remediation, Vol.21, No. 4, 124-132. 